\title{
2
}

\section{DIALÉTICA E LINGUAGEM EM PLATÃO}

Jayme Paviani

SÍNTESE - Exposição introdutória da dialética de Platão e estudo da relação dialética e linguagens no diálogo Sofista, e das relações entre dialética e analitica a partir de alguns aspectos da Carta sobre a Dialética de Carlos R. Cime Lima.

Palavras-chave: Dialética, dialética e analítica, dialética e linguagem.
This paper is an introductory exposition of Plato's dialectic and at same time a study about the dialectical relation and language in the Sophitês and still about relations regarding to dialectic and analytic, starting from some aspects of Dr. Cime Lima's Letter about dialectic.

Key-words: dialectic, dialectic and analytic, dialectic and language.

A dialética em Platão não é um tema que possa ser estudado independentemente de sua filosofia. É um modo (método) de conhecer, de filosofar, através da mediação de conceitos (Idéias). Dialética é mais do que uma técnica de pergunta e resposta, mais do que uma "investigação lógica" ou demonstração no sentido matemático, mais do que diálogo empírico, é o "caminho" que conduz à posse da verdade, o "exercício" de desprendimento do sensível para alcançar o inteligivel, especialmente a Idéia de Bem. É a preparação para a sabedoria. A dialética enquanto modo de pensar e conhecer não se dá numa simples definição e num único momento. Ela pressupõe um aprendizado, um desenvolvimento e um amadurecimento intelectual e emocional. A lição desse processo está nos diálogos de Platão, os quais tiram proveito da forma literária e dos ensinamentos por etapas, apresentando a dialética em sua formação e, ao mesmo tempo, mostrando suas relações com as questões filosóficas relevantes, de modo direto, como no diálogo Sofista e, de modo indireto, como no Teeteto, mas sempre presente, como a seiva que vivifica o sistema.

Segundo Aristóteles a dialética foi "inventada" por Zenão de Eléia talvez com a finalidade de resolver as antinomias hipotéticas de Parmênides. Essa notícia, dada por quem não segue a dialética e a reduz a uma função secundária no processo de conhecer, representa de certa maneira uma recepção comprometida da dialética de Platão. Aristóteles faz uma crítica lógica da dialética de Platão, opõe à dialética a analítica. Mas, é necessário observar que o tipo inaugural de dialética, a dos eleatas e dos sofistas, segundo Platão, é uma "erística" ou disputa (Sofista, 224 e 226 a, República 499a, Fedro 261 c). Platão transforma o modo de conhecer erístico num método filosófico superior, capaz de incorporar a totalidade no processo de pensar, isto é, a unidade na multiplicidade. Para isso, precisa ir além do simples jogo de 
palavras e questionar concomitantemente as possibilidades do conhecer, do discurso e do acesso ao real. Realiza essa tarefa ao criticar Parmênides por atribuir ser somente ao que é, e negar o ser ao que não é e, assim, separar o ser dos fenômenos, anular o mundo real.

Parmênides elabora o princípio da verdade nos seguintes termos: o ser é e não pode não ser, o não ser não é e não pode ser de modo algum. E desse princípio conclui que o ser é a única coisa pensável e exprimível e, portanto, ser e pensar são o mesmo, só é possivel pensar o ser. Zenão de Eléia, discípulo de Parmênides, sem questionar a posição do mestre, torna-a absoluta procurando desenvolver várias técnicas de argumentação e principalmente a demonstração por absurdo, ao argumentar contra o movimento e a multiplicidade na defesa da tese. Platão, no Sofista, mostra que o não ser também é, e desse modo, sem separar o conhecer, a linguagem e a realidade em três momentos autônomos, procura articulá-los com o desenvolvimento de uma dialética que não mais se perde no particular, mas que conhece a verdade da realidade na universalidade do pensar, livre da percepção sensorial.

A dialética de Platão mostra que a disputa, o debate, praticado pelos sofistas, influenciados por Zenão, tende a cair em suas próprias armadilhas. Os sofistas transformam a argumentação dialética numa simples técnica da erística, da contradição, da contestação, da luta, da aquisição (Sofista, 226 a). O conteúdo do argumento torna-se secundário. Em conseqüência, também sua dimensão ética é vista como acidental. Por isso, Platão chama de sofista aquele que argumenta a favor de qualquer opinião, com o objetivo de receber dinheiro. Mostra que os oradores nos tribunais fazem parecer ora justas ora injustas as mesmas coisas às mesmas pessoas (Fedro, 261 c). Não empregam os recursos do convencimento, mas usam a retórica persuasiva para criar ilusões. Somente o filósofo é dialético, é o único que sabe lidar com as Idéias.

A passagem da argumentação retórica dos sofistas para a dialética é mediada pelo desenvolvimento do método socrático da pergunta e da resposta. O diálogo prepara a dialética. Diálogo deriva de dialegeszai que significa conversar. Porém, não se trata de um conversar de qualquer modo ou sobre qualquer coisa. Implica saber discernir especialmente entre o bem e mal, entre o verdadeiro e $o$ falso. A noção de dialética pressupõe o saber distinguir e classificar, a partir dos princípios racionais presentes no pensamento humano (alma). No Crátilo, Platão mostra que só o dialético sabe interrogar e responder. No Fedon, mostra que quando se fala faz-se referência a uma "essência" de cuja existência se fala nas interrogações e nas respostas. Isto quer dizer que não é qualquer diálogo (conversação) que pode ser qualificado de dialético. A dialética supõe o abandono do método seguido pelos filósofos naturalistas pré-socráticos, isto é, requer a substituição das causas naturais pela procura da "causa verdadeira", a renúncia da percepção sensorial pela visão intelectual e "intuitiva" dos "Princípios", do Demiurgo (ou Inteligência) e das Idéias.

A dialética funda-se nos logoi, ao menos em dois logoi, duas posições que permitem o confronto e sucessivas mudanças de "teses" ou "hipóteses" para se alcançar a solução. Só a partir deles, do sentido dialético do diálogo, pode-se estabelecer como fundamento o Belo em si, o Bom em si, o Grande em si, e assim por diante (Fedon, 100 a,d). Não se pode praticar a dialética sem as Idéias e não se al- 
cança as Idéias (Formas inteligiveis) sem a dialética. Nesse sentido, Platão usa as expressões "visão da mente" ou "visão da alma" para caracterizar o ver intelectivo, o conhecer dialético que ao mesmo tempo implica a "intuição intelectual" da Idéia (objeto visto, Forma) e o voltar-se para dentro de si, da própria alma.

Há uma grande afinidade entre a alma e as Idéias. A alma aproxima-se mais ao divino, ao imortal, ao inteligível e ao imutável e o corpo se parece mais com 0 humano, o mortal e a mudança (cf. Fedon, 80). Sendo a alma uma espécie de intermediária entre as Idéias e os objetos sensíveis, tendo também seu ser verdadeiro (cf. Sofista, 248 e, 249 b), como as Idéias, está pressuposto que ela as conhece.

A prática da dialética pressupõe a articulação de todos os elementos do sistema filosófico. Platão não apresenta um sistema filosófico tão completo quanto o de Hegel, mas como o hegeliano é método e conteúdo pensado (cf. Weber, 1993: 1544). Em termos tradicionais é possivel dizer que na dialética estão presentes, fundidos num único movimento, aspectos ontológicos, gnosiológicos, antropológicos, cosmológicos, éticos e outros. Ao mesmo tempo que as Idéias se apresentam caracterizadas pela inteligibilidade, incorporidade, imutabilidade, unidade, etc., o fenômeno da anamnese (da maiêutica socrática) revela os diversos graus do conhecimento caracterizados segundo a natureza (as funções) da alma. Nesse entrelaçamento entre a natureza das Idéias e a natureza da alma, as formas de conhecimento que Platão expõe na República, a doxa e a episteme, articulam-se com os graus da realidade, desde o sensivel até o inteligível. Para chegar à intelecção (noesis) da idéia de Bem é necessário passar pelo entendimento discursivo (dianoia) dos objetos matemáticos, e isto só é possivel após a superação das fases do conhecimento da opinião (doxa), isto é, da crença (pistis) nos objetos sensíveis e da imaginação (eikasia) das imagens sensíveis. O homem comum, portanto, ao deter-se na opinião não pensa dialeticamente. Nem o matemático ao usar o entendimento. $\mathrm{O}$ dialético situa-se no mais alto grau e nele "capta" as Idéias, suas relações dialéticas e, finalmente, pode intuir a Idéia de Bem, o Uno.

Platão, no último período de sua filosofia, descobre uma correlação entre as funções da alma e os objetos geométricos, mas a relação entre o conhecimento matemático e a dialética surge no Protágoras (356 e), na República, em diversas passagens e em outros diálogos. A matemática é a ciência da medida que permite acesso ao inteligivel, mas só a dialética estuda as relações de grandeza em função da Justa Medida. Enquanto a matemática, procede em busca de uma conclusão, a dialética rejeita uma a uma as hipóteses para alcançar o Princípio de todas as conclusões possíveis (República, VII, 533). Além de alcançar a "essência de cada coisa" (cf. República, VII, 534 b), a dialética permite alcançar, numa "visão sinótica" de todas as essências das coisas, o Uno, o Bem.

Há uma dialética das Idéias em si e uma dialética que relaciona o mundo sensível e o inteligível mediado pela categoria da participação. A noção de participação, fundamental no sistema platônico, tem a função de resolver principalmente o problema da relação entre as Idéias (Formas) em si (Gêneros Supremos) e, segundo alguns comentaristas, a relação entre as Idéias e as coisas sensiveis. No Parmênides, por exemplo, não se esclarece se a coisa sensivel participa da totalidade ou só de uma parte da Idéia. No Sofista, Platão, sem essa divisão, mais coerente com o pensamento dialético, mostra que as Idéias são entidades que podem repartir-se 
sem perder a unidade. Diz: "Nada impede ao que assim é dividido de ter uma unidade que se sobreponha ao conjunto de suas partes e de ser, dessa forma, não apenas total, mas também una" (245 a). Deixando de lado, por ora, o problema da participação, é possível admitir que a dialética platônica pode ser considerada em dois planos: a) o das Idéias e b) o da relação das idéias com o mundo sensível. Em conseqüência, há uma dialética ascendente e uma descendente. No Fedon e na República a dialética apresenta-se como uma ascensão progressivamente mais sinótica (abrange vários aspectos num só momento), indo do sensível ao inteligivel, e no Fedro, no Parmênides, no Sofista e no Filebo a dialética é mais diacrítica e descendente, apresenta-se como um método de dedução racional das Idéias. Especialmente no Fedro a dialética é apresentada em dois momentos: a) da reunião, sintese (synagoge) e b) da divisão (diairesis) (265 c -266 b). Reunião e divisão constituem realmente o processo dialético em sua totalidade. O processo "diairético" é exemplificado nos diálogos Sofista, Político e Filebo. No procedimento dialético ascendente, sinótico, livre dos sentidos e do sensível, alcança-se as Idéias e, em seguida, de Idéia em Idéia pode-se chegar à Idéia suprema. Em outros termos, passo a passo a multiplicidade é resolvida na unidade. Platão, na República, diz claramente que o método dialético procede pelo caminho que consiste em afastar as hipóteses até alcançar o Princípio que confere solidez. Nesse processo eleva-se ao alto "o olhar da alma, mergulhado num pântano bárbaro, usando as artes das quais temos tratado (isto é, as matemáticas) como coadjuvantes nessa conversão" (Livro VII, 533 c-d). A reunião indica a operação que consiste em captar a propriedade de algo.

No procedimento dialético descendente parte-se da Idéia suprema ou de Idéias gerais e por divisão (processo "diairético") distingue-se Idéias particulares contidas nas Idéias gerais, e examinando as articulações nas quais se desdobram, alcançam-se as Idéias que não incluem em si outras Idéias, para finalmente estabelecer o lugar de cada Idéia na estrutura hierárquica do mundo ideal.

O procedimento dialético exige uma formação dialética do filósofo. Platão, na República, menciona o ciclo ideal dessa formação (535 e 536) e essas condições indiretamente remetem ao problema moderno da relação objetividade-subjetividade relativamente ao conhecer, ao falar (linguagem) e ao acesso do real. Em Platão, de certo modo, está presente toda a filosofia ocidental. Considerado o contexto histórico e as recepções do pensamento platônico na cultura ocidental, continua sendo um desafio a leitura e a interpretação de seus diálogos. Tal leitura não suporta as recepções dualistas (idealismo ou realismo), as divisões abstratas. Um sistema filosófico oferece uma dupla face, uma explícita e outra implícita. Mostrar a primeira é tarefa de um esforço técnico, típica dos grandes comentaristas. Desvendar a segunda é função dos filósofos e dos que possuem a coragem da "especulação", dos que se situam mais próximos do filosofar do que da filosofia. Afinal, Platão sistematizou a filosofia, deu unidade à multiplicidade das questões filosóficas anteriores, mesmo ao oferecer um sistema aberto, em seus textos com finalidade de ensino. O problema de ser ou não uma dialética finalista (direcionada pela Idéia de Bem) precisa ser examinado num contexto maior, pois, a dialética é ao mesmo tempo uma teoria do ser, do conhecer, do agir. 
Esses pressupostos permitem examinar se a filosofia de Aristóteles (e as demais filosofias) é ou não é uma variação da filosofia platônica, antes de ser simplesmente uma outra filosofia, e se, entre tantos outros problemas filosóficos, o modo dialético de pensar já não contém as possibilidades dos modos analíticos (lógicos) e hermenêuticos. Afinal, os processos da reunião (sinagoge) e da divisão (diairesis) possuem uma analítica implícita, pré-teórica, porém que jamais se reduz ou realiza o processo analítico puro. Platão de fato, após a "análise", retorna imediatamente à síntese. Por isso, se hoje podemos caracterizar a dialética, a analítica e a hermenêutica, cada uma com seu perfil, esboçado no decorrer da história da filosofia, talvez seja porque a dialética de Platão já contenha, em seu estado nascente, as possibilidades de outros modos de pensar associados ao modo predominantemente dialético de pensar.

A melhor maneira de mostrar esses pressupostos é confrontar a questão da dialética e da linguagem em Platão. Já de início podemos observar, por exemplo, que para dizer o que é a dialética, mesmo usando o diálogo como gênero de obra, torna-se necessária a linguagem analítica e a linguagem hermenêutica. Apesar disso, é necessário partir de uma caracterização preliminar de cada um dos modos de conhecer e de dizer. Cirne Lima, em "Dialética e Evolução", mostra as características lingüísticas dos analíticos e dos dialéticos e como ambos precisam uns dos outros para se expressarem. Há um momento em que dialética e analítica se entrelaçam. O mesmo se pode dizer da hermenêutica em relação aos modos de conhecer, de falar (dizer) e de acesso à realidade. Sob este prisma, a tese de Cirne Lima é original não apenas na tentativa de articular os três modos, embora não fique claro como a hermenêutica pode de fato concretizar-se em relação aos outros dois, mas principalmente ao propor as bases de um sistema que incorpora as contribuições atuais e parciais das reflexões filosóficas. Trata-se da elaboração de um sistema filosófico que pretende aproveitar as contribuições filosóficas (mesmo fragmentadas) do século XX. Meta ambiciosa, porém legítima e natural para quem não reduz a filosofia a um mero exercício técnico ou a uma reflexão privilegiada. Para demonstrar a relevância dessa posição é possível mostrar como em Platão a dialética não é só um "jogo de opostos", mas um pensamento ao mesmo tempo que aproveita os processos analiticos e hermenêuticos.

Para começar é preciso caracterizar os modos de argumentar dos analíticos e dialéticos, suas "línguas diferentes com sintaxes diferentes". Cirne Lima, diz: "Os analíticos, para dizer e expressar algo, utilizam frases ou proposições compostas de sujeito, predicado e cópula (respectivamente de argumento e função); somente tais construções sintáticas possuem um valor de verdade, apenas elas, não os conceitos, são verdadeiros e falsos. Na linguagem dialética, porém, tais proposições compostas de sujeito e predicado não são, via de regra, utilizadas na argumentação. As "idéias" de Platão e os "conceitos" de Hegel possuem sempre um valor de verdade e sempre apresentam algo como verdadeiro ou falso (as idéias se atraem mutuamente, elas entram em conflito e se repelem, elas se conciliam e se reunificam), mas quase nunca se desdobram explicitamente em sujeito e predicado" (1995, p. 701).

O entrelaçamento entre dialética, analítica e hermenêutica pressupõe igualmente a caracterização da linguagem hermenêutica. Na linguagem analítica o valor de verdade está na proposição entendida de modo lógico, na linguagem dialéti- 
ca está nos conceitos que formam a proposição. A linguagem hermenêutica considera ao mesmo tempo os conceitos e a estrutura lógica da proposição ao trabalhar com relações judicativas, isto é, a proposição, conforme Heidegger, em Ser e Tempo, é um modo derivado da interpretação ou "estrutura" constitutiva de toda compreensão e interpretação (1988, p. 204 a 218). Heidegger atribui ao fenômeno da proposição três significados derivados: demonstração, predicação e comunicação. A linguagem como efetivação do discurso apresenta possibilidades de demonstração e de comunicação que ultrapassam os mecanismos lógicos da gramática. Nesse sentido a linguagem hermenêutica não é um instrumento que se pode manipular de modo objetivo, pois o homem não apenas possui linguagem, ele é fundamentalmente linguagem. A linguagem é ao mesmo tempo gesto e palavra, fenômeno existencial e fenômeno conceitual. Tais dimensões da linguagem parecem ser hoje demonstradas pelos estudos biológicos e psicológicos das operações e habilidades mentais. Linguagem é ao mesmo tempo natureza e cultura. Gadamer, em Verdade e Método, mostra, por exemplo, que pertencer a uma tradição significa passar pela interpretação dos signos, dos textos, nos quais se inscrevem e se oferecem à nossa decifração as heranças culturais. Assim, a linguagem hermenêutica tem uma peculiar compreensão da proposição que envolve ao mesmo tempo os aspectos analíticos e dialéticos, afinal, a linguagem é o único ato humano auto-referente.

Os modos de conhecer (e conseqüentemente de linguagem e de concepção da realidade) dialético, analítico e hermenêutico não podem existir em estado puro. Um depende dos outros. Observa-se apenas uma predominância de um sobre os outros. E é dessa predominância que resulta um modo peculiar de cada um desenvolver o conhecer, a linguagem e conceber a realidade. Mas, isto é uma questão específica que merece uma abordagem própria. Por ora, interessa mostrar que Platão, no Sofista, oferece um exemplo de entrelaçamento entre linguagem dialética e analítica.

A tentativa de resolver o conflito entre a unidade e a multiplicidade, tematizado desde o diálogo Menon, leva Platão a articular três problemas fundamentais de sua filosofia: o modo de conhecer dialético, a linguagem e a teoria das Idéias.

Nos primeiros diálogos, como já foi mencionado, Platão procura a definição do belo, do virtuoso, do corajoso e assim por diante. Nesse esforço, dá-se conta de que é necessário para alcançar a definição verdadeira procurar o belo em si, a virtude em si, a coragem em si. Tal procura acaba necessariamente na elaboração da teoria das Idéias, apresentada, primeiro, nos diálogos Fedon e República e, segundo, no Parmênides e Sofista. Concomitantemente à elaboração da teoria das Idéias e ao desenvolvimento do processo dialético, Platão esboça uma concepção da linguagem nos diálogos Crátilo, Fedro, Sofista e outros. A linguagem perde gradualmente o caráter mágico, sacro e associa-se ao processo do conhecimento. No final do Crátilo, Platão adverte que é necessário deixar de lado os nomes e voltar-se para as coisas. No Parmênides e no Sofista, substitui a (teoria da) nomeação pela enunciação e apresenta, ao mesmo tempo, a dialética em seu estado mais elaborado.

O processo "diairético", a teoria dos Gêneros Supremos e a questão da linguagem permitem a definição do sofista e do filósofo, distinguindo-os em relação ao 
bom e ao mau uso da dialética, em relação ao uso dialético da linguagem, isto é, racional e não persuasivo, e em relação à solução do problema da unidade e da multiplicidade. Platão quer superar a falsa arte da erística da contradição. O Ser absoluto de Parmênides, o Devir de Heráclito e as demais explicações da filosofia pré-socrática são superados pelo Ser visto na oposição dialética do Repouso e do Movimento e esta na oposição dialética da Identidade (Mesmo) e da Diferença (Alteridade ou outro) e, assim, argumentando que o não ser também é, torna-se possível o discurso falso. Como conseqüência torna-se igualmente possível demonstrar que a multiplicidade (o ilimitado) seja medido pela unidade (Uno) no juízo, isto é, na linguagem.

A leitura rigorosa (analítica e hermenêutica) do Sofista mostra a complexidade das relações entre dialética e discurso (linguagem) tanto em relação aos Gêneros Supremos quanto em relação as Idéias e o mundo sensível. O longo intermezzo do diálogo dedicado ao problema do erro e à questão do não ser, nas palavras de Platão, consiste no "mostrar e parecer sem ser, dizer algo sem dizer com verdade" (237 a). A solução exige que se demonstre, contra Parmênides, que, "em certo sentido, o não-ser é, e que, por sua vez, o ser, de certa forma, não é" (242 d-e). A resposta está na possibilidade do discurso falso.

A possibilidade do discurso falso, demonstrada contra os sofistas, articula dialética e linguagem sob diversos aspectos. É possivel salientar especialmente três aspectos: a) a linguagem dialética (mediação de Idéias) distingue-se da linguagem lógica; b) apesar disso, a dialética precisa demonstrar seu processo de argumentação através da linguagem analítica de tipo lógico e gramatical; e c) a dialética precisa para formular seus "conceitos" ou "proposições" do processo hermenêutico (cf. Cirne Lima, "Dialética e Evolução", item 4).

Quanto a esses aspectos, Cornford, ao contrário de Taylor, afirma categoricamente que a dialética de Platão não se caracteriza como Lógica Formal. Ela não usa símbolos e nem constrói formas proposicionais no sentido lógico. Esta afirmação de Cornford atende o ponto de vista (a), isto é, de que a dialética não fala a mesma língua da analítica. Entretanto, Cornford reconhece que a estrutura imutável das Idéias ou Gêneros, eternamente combinadas ou separadas no sistema da Verdade ou Realidade, são os significados convencionalmente associados aos nomes comuns. Admitida tal premissa, é possivel concluir que a transposição dos significados das Idéias ou Formas para o significado dos nomes ocorre mediante uma interpretação hermenêutica, atendo-se assim ao ponto de vista (b). Por sua vez Gadamer mostra que a dialética de Platão, nesse caso longe da dialética de Hegel, instaura a contradição em cima da Lógica Formal, pois, no Sofista encontra-se a mais importante prefiguração da célebre fórmula do princípio da contradição que Aristóteles estabeleceu no livro IV da Metafísica (1988: 34), e isto, em parte, atende ao ponto de vista (b).

O ponto de partida de Platão, no Sofista, para resolver a questão do erro no discurso (linguagem) são duas afirmações nucleares: a) o discurso nasce do mútuo entrelaçamento das Formas (Idéias) (259 e); b) o discurso é de tal natureza que é possivel demonstrar que o não-ser é (260 a). A relevância dessas questões reside no fato de que a filosofia, para existir, depende de sua solução. Além disso, na exposição de Platão demonstra-se a possibilidade de uma má dialética, própria da sofísti- 
ca e da erística, que consiste num mero jogo de opostos que aniquila o discurso em sua gênese. Nesse sentido, o Estrangeiro, diz: "Mostrar não importa como, que o mesmo é o outro, e o outro, mesmo; o grande, pequeno; o semelhante, dessemelhante, sentindo prazer em apresentar perpetuamente essas oposições nos argumentos, isso não constitui a verdadeira crítica: é apenas, evidentemente, o fruto prematuro de um primeiro contato com o real" (259 d).

Afirmar que o discurso (linguagem) nasce do entrelaçamento (symplokè) das Formas (259 e) significa que há um momento hermenêutico na dialética, conforme propõe Cirne Lima, pois, os predicados da proposição dialética são conceitos "oriundos do espaço onde se encontram todas as proposições" (cf. Carta sobre a Dialética, item 4). Mas, há também um momento analítico, pois, conforme Gadamer, citando Hegel, o Sofista não apresenta uma dialética "pura", porque parte de proposições supostas, que não são, como tais, derivadas umas de outras em sua necessidade (1988: 13 e 14).

Cornford vê os enunciados como expressões verbais do pensamento e do juízo constituídos de nomes e verbos que, mesmo sendo considerados apenas um recurso da estrutura gramatical, (sem mencionar a cópula, nem sempre usada em grego), mostram a necessidade da dialética de Platão empregar recursos analíticos. É correto afirmar que a dialética não usa modelos simbólicos, figuras, e nem o enunciado no sentido lógico. Mas, só é possível mostrar a hierarquia do mundo das Idéias e sua relação com o mundo sensível através dos processos de reunião e de divisão, numa linguagem de articulação lógica e gramatical, embora Platão sempre procure, após a análise, a síntese. As operações da divisão e da reunião ou composição (Fedro, 265 a, 266 b) alcançam sentido dialético, no Sofista, a partir dos princípios do Uno e da Díade e da hierarquização das Idéias na exposição dos Gêneros Supremos. Sem essa referência, de fato, a dialética seria uma simples análise formal.

Platão, no Sofista, não se refere mais a uma dialética que parte das letras e das sílabas como elementos (stoijeion) da realidade, como no Crátilo, mas parte da união do nome e do verbo. Tal mudança permite contextualizar as proposições "Teeteto está sentado" e "Teeteto voa" usadas por Platão para demonstrar a possibilidade do discurso falso e, nesse caso, para mostrar como a linguagem analítica possibilita o pensamento dialético.

Os enunciados falsos podem ter algum significado. Eles não são, como pretendem os sofistas, um dizer nada ou falar nada ou simplesmente um dizer coisas que não são. Platão demonstra que o "que não é" não significa apenas o "que não existe", mas pode significar também o "que é diferente". O argumento demonstrativo está no entrelaçamento (symplokè) das Formas ou Idéias que dão origem ao discurso. Na organização do argumento surgem diversas dificuldades: a) o do entrelaçamento das Formas (Idéias) e dos nomes; b) o da relação de compatibilidade ou incompatibilidade entre as Formas (Idéias); c) o do entrelaçamento das Formas (Idéias) não ditas e dos Gêneros Supremos; d) o da relação entre a natureza do discurso com o não-ser. Esses e outros problemas já foram interpretados por diversos especialistas como Cornford, Ackrill, Moravcsik e Ray, e reexaminados por Movia.

Platão mostra que todo enunciado é complexo, mesmo o mais simples contém um nome e um verbo. A palavra é um "sinal vocal" que diz, indica ou significa (ver- 
bos usados por Platão sem muito rigor) algo, no sentido de (a) um nome comum apontando uma Forma (Idéia) de coisas existentes e, de (b) um nome próprio que indica somente uma coisa existente (cf. Cornford, 1964). Nos exemplos "Teeteto está sentado" e "Teeteto voa", o primeiro é considerado verdadeiro e o segundo, falso. Teeteto é o sujeito de ambos e é um indivíduo e não uma Forma (Idéia), tem existência sensivel. $O$ enunciado verdadeiro parece não oferecer dificuldades, pois tanto o sujeito como o predicado indicam fatos existentes. Não se pode dizer o mesmo do enunciado falso, pois, se Teeteto está sentado não pode estar voando. Mas, Platão não aceita a afirmação dos sofistas de que "Teeteto voa" é um enunciado sem significado e não um enunciado falso. Para Platão, "sentado" e "voando" são Formas e, nesse caso, a Forma "voando" oferece um significado ao enunciado, embora aponte para um fato não existente. Em outros termos, para Platão a Forma (Idéia) "voando" é simplesmente diferente da Forma "sentado".

Cornford explica o entrelaçamento entre as Formas como uma espécie de "coexistência", de relação simétrica, enquanto a relação entre sujeito e predicado é uma relação não simétrica e, ainda, Cornford sustenta que o enunciado deve ser interpretado não no sentido de que as Idéias são os únicos elementos de significado de cada discurso, mas no sentido de que cada proposição implica o uso de alguma Forma. Segundo Movia, esta interpretação apresenta dificuldades, pois o entrelaçamento menciona Formas e não nomes e verbos, como no próprio diálogo, adiante, explica. Parece que Platão, para demonstrar que o discurso nasce do entrelaçamento das Formas, precisa da estrutura gramatical do enunciado, apesar de ir além dos aspectos lógicos da proposição. Diz: "O conjunto formado de verbos e de nomes, que anuncia, a teu respeito, o outro como sendo o mesmo, e o que não é como sendo, eis, exatamente, ao que parece, a espécie de conjunto que constitui, real e verdadeiramente, um discurso falso" (263 d). Observa-se nessa afirmação, sem dúvida, o uso da linguagem dialética (através da mediação das Idéias de Identidade e Diferença) e o uso da linguagem analítica própria da estrutura gramatical.

Platão, no Sofista, supera os fonemas e as letras que compõem a linguagem dos nomes apresentada no Crátilo, propondo claramente o problema da função proposicional, embora permaneça preso à concepção nome e verbo. Os verbos (rhemata) são a unidade que exprimem ações. Os nomes (onómata) indicam os sujeitos dessas ações. E a seqüência de só verbos ou só nomes não forma uma proposição, um discurso, pois é preciso a combinação entre nomes e verbos e necessariamente o discurso precisa ser sobre ou de algo. Com essas e outras noções, Platão enfrenta o problema do não-ser e do erro na opinião e no discurso.

As dificuldades relativas à constituição proposicional provém ou de ordem conceitual (oposição de Idéias) ou de ordem lógico-gramatical (conjunto de sujeito e predicado). No primeiro caso, a argumentação emprega os Gêneros Supremos e, no segundo, a demonstração se faz através do uso de nomes e verbos. Porém, Platão não estabelece essa distinção e, por isso, sua linguagem "funde" as duas ordens de argumentação, a dialética e a analítica. Também não tem consciência de que a passagem entre $o$ entrelaçamento das Formas e a combinação nome e verbo no enunciado exige um esforço hermenêutico, embora o nome e o verbo não correspondam à relação sujeito e predicado. A proposição lógica é um erunciado que pode ser verdadeiro ou falso e no sentido gramatical é uma unidade sintática cons- 
truída em torno de um verbo e que pode ser uma frase simples ou complexa, ou um elemento de frase complexa. O nome e o verbo, em Platão, nem sequer caracterizam o sentido lingüístico de frase, pois existem frases, na gramática moderna, sem verbo (palavra-frase). Entretanto, fora esses detalhes, é necessário recordar que Platão, no diálogo Ion, fala da necessidade de "aprofundar o pensamento e não apenas as palavras" (530 c) para o rapsodo interpretar o pensamento do poeta. No Sofista, "aprofundar o pensamento" consiste em usar as mediações dialéticas dos Gêneros Supremos para explicar a possibilidade do discurso falso ou para demonstrar que o não-ser é. $\mathrm{O}$ entrelaçamento das Formas no discurso dependem da dialética dos Gêneros e da estrutura gramatical.

Um maior esclarecimento dessa questão passa pela comparação entre as concepções conhecimento-linguagem em Platão (método dialético) e em Aristóteles (método analítico). Aristóteles não se envolve nas concepções naturalistas ou convencionalistas da linguagem (cf. Paviani, 1993). Procura diminuir a distância entre as palavras, a representação lingüística e as coisas. De um modo claro e resumido, Domingues, diz: "A exemplo de Platão, Aristóteles interpõe entre as palavras e as coisas a representação e faz da linguagem uma representação, a representação de uma representação. Mas, à diferença de Platão, a linguagem está colada no pensamento e na coisa mesma: de um lado, a linguagem não é um instrumento heterogêneo à matéria a que se aplica - representação - em sua qualidade de expressão sensível-extra-sensivel - signo - mas o veículo (forma) do pensamento ou o seu duplo homogêneo; de outro lado, a linguagem é uma representação, não uma representação no sentido platônico, com fundamento ante re (idéia), mas com fundamento in re ou na coisa mesma ("A linguagem é a linguagem do ser", diz Aristóteles com Antístenes)" (1991: 134). O modelo lógico-metafísico da linguagem de Aristóteles une o ser e o conceito na unidade da proposição e não através da palavra (signo) tomada isoladamente. Embora Platão também afirme a proposição como unidade básica do discurso, a união entre os nomes e os verbos, a gênese do discurso está no entrelaçamento das Formas. Quando Platão diz que o nome indica ação e o verbo, o sujeito da ação, aponta para o fato de nome e verbo receberem 0 significado da coisa (ousia) (262 a), isto é, o significado da proposição não provém das implicações lógico-sintáticas, mas das Idéias.

Não há dúvida de que, em Platão, a natureza do discurso (linguagem) possui uma unidade sintática e semântica e que a proposição realiza essa unidade, mas 0 significado do discurso tem um sentido especial. A possibilidade do discurso falso depende do discurso ser necessariamente sobre algo e não sobre nada (262 e) e depende de um valor de verdade (ser verdadeiro ou falso) que está fora da proposição (263 a-c). Platão concorda que os enunciados "Teeteto está sentado" e "Teeteto voa", o primeiro é verdadeiro porque se atribui ao sujeito um predicado adequado e o segundo é falso porque o predicado não é adequado. Os dois enunciados seguem as regras sintáticas e possuem significado. Entretanto, o verdadeiro é verdadeiro porque a Forma "sentado" corresponde a Teeteto e a Forma "voa" não corresponde.

Talvez outros exemplos de enunciados possam dificultar a caracterização das implicações dialéticas e analíticas. Tais dificuldades podem aumentar à luz dos conhecimentos de lógica e lingüística atuais. Todavia, o objetivo deste estudo pretende apenas mostrar como em Platão (ou já em Platão) os modos de conhecer dialéti- 
co, analítico e hermenêutico, de certa maneira, associam-se e complementam-se. Nenhum deles pode desenvolver-se em estado puro. Tem razão Cirne Lima ao afirmar que há um lugar, um momento interno em que um se entrelaça com outro. E isto, entre outras conclusões, permite examinar a dialética de Platão sob novos enfoques.

O sentido pejorativo de dialética, de Aristóteles até Kant, compreendida como uma técnica ou uma lógica da ilusão, e o sentido ideológico de dialética, devido aos mal-entendidos do marxismo contemporâneo, somam-se às dificuldades de uma leitura rigorosa dos verdadeiros textos dialéticos. Nesse aspecto, Cirne Lima, em "Dialética e Evolução", reintegra a dialética no pensar filosófico e na investigação científica, conjuntamente com a analítica e a hermenêutica. Trata-se, por enquanto, de um projeto, de uma contribuição que rompe os processos imanentes da vida acadêmica para propor, numa época de fragmentações, a elaboração de um novo sistema racional. É natural que o novo crie insegurança, polêmica, recusas. Isto, aliás, faz parte do filosofar e também da revisão das recepções históricas da filosofia. Novas propostas para entender a filosofia do presente e do futuro requerem uma releitura dos textos do passado. As novas idéias em filosofia podem ser testadas nas filosofias da tradição. As rupturas são determinadas como tais no interior da própria filosofia vista globalmente. Não existe o absolutamente novo. Existe a explicitação de novos aspectos, o desenvolvimento de processos implícitos, não plenamente objetivados. Por isso, em Platão, como em Aristóteles, as origens do filosofar definem a natureza da filosofia: nenhuma filosofia está acabada, nenhum conteúdo é dado fora do método, todo conhecimento é ao mesmo tempo linguagem e realidade. $\mathrm{O}$ filosofar é ao seu modo uma constante gênese.

\section{Referências bibliográficas}

CIRNE LIMA, C. R. V. Carta sobre a dialética. Porto Alegre: PUCRS, 1994.

. Dialética e evolução. Porto Alegre: PUCRS, 1995.

DOMINGUES, I. O grau zero do conhecimento. São Paulo: Edições Loyola, 1991.

HEIDEGGER, M. Ser e Tempo, parte I. Trad. de Márcia de Sá Cavalcante. Petrópolis: Vozes, 1988.

GADAMER, H. G. Verdad y metodo, fundamentos de una hermenêutica filosófica. Salamanca: Segueme, 1984.

- La dialetica de Hegel. Madrid: Cátedra, 1988.

PLATON. Oeuvres complètes, t. VIII, Le Sophiste. Texte établi et traduit par A. Diès. Paris: Belles Lettres 1963.

CORNFORD, F. M. Plato's theory of knowledge. The Theaetetus and the Sophist, Translated with a Running Commentary by F. M. C. London, 1964.

MOVIA, G. Apparenza, et esse e veritá, commentario storico filosofico al "Sofista" di Platone. Milano: Vita e Pensiero, 1991.

WEBER, T. Hegel: Liberdade, estado e história. Petrópolis: Vozes, 1993. 